\title{
PERCEPÇÃO DOS MORADORES SOBRE AS ARARAS-CANINDÉ (Ara Ararauna), NA ÁREA URBANA DE CAMPO GRANDE (MS)
}

\author{
Aline Calderan ${ }^{1}$ \\ Larissa Tinoco ${ }^{2}$ \\ Celso Correa Souza ${ }^{3}$ \\ Neiva Maria Robaldo Guedes ${ }^{4}$
}

Resumo: Estudo sobre percepção ambiental se faz necessário para compreender a relação do homem com a natureza e promover a sensibilização para conservação. O objetivo desta pesquisa foi analisar a percepção dos moradores sobre as araras-canindé (Ara ararauna) na área urbana de Campo Grande, Mato Grosso do Sul, bem como sensibilizar a população para a necessidade de praticar a conservação da biodiversidade. A coleta ocorreu em 2017 e 2018, com 423 moradores. A idade, o sexo, a escolaridade e a região onde moram, não influenciou a percepção dos moradores, todos consideram que as araras são importantes e geram muita visibilidade para a cidade.

Palavras-chave: Aves; Psitacídeos; Educação Ambiental; Conservação.

${ }^{1}$ Universidade Anhanguera Uniderp. Instituto Arara Azul. E-mail: alinecalderan.adm@hotmail.com.

2 Instituto Arara Azul. E-mail: larissabarbosatinoco@gmail.com.

3 Universidade Anhanguera Uniderp. E-mail: csouza939@gmail.com.

${ }^{4}$ Universidade Anhanguera Uniderp. Instituto Arara Azul. E-mail: guedesneiva@gmail.com

Revbea, São Paulo, V. 14, № 2: 277-294, 2019. 


\section{Introdução}

Em contato com o meio ambiente, as pessoas fazem uso dos sentidos e através deles recebem estímulos externos que são conduzidos até o cérebro, dando origem a percepção. Com isso pode-se perceber as paisagens de diversas maneiras e construir a realidade através de experiências únicas, ou seja, cada indivíduo percebe, reage e responde de maneira diferente as ações do meio em que vive (MELAZO, 2005; TUAN, 2012). Percepção ambiental é a tomada de consciência que o homem adquire em relação ao ambiente, ou seja, é $\mathrm{o}$ ato de perceber $\mathrm{o}$ ambiente em que está inserido e aprender a cuidar do mesmo da melhor forma possível (TRIGUEIRO, 2003; FAGGIONATO,2005).

Desta maneira se torna importante o estudo sobre percepção ambiental para que se possa compreender melhor a relação entre o homem e o ambiente, saber se está satisfeito ou insatisfeito, para tentar promover a sensibilização e ajudá-lo a compreender 0 ambiente ao seu redor (FERNANDES et al., 2004; MELAZO, 2005). A educação ambiental se torna um importante aliado na conscientização para a necessidade de se conservar a fauna e flora do ambiente, com a ajuda dela, pode-se desenvolver o senso crítico e a criação de métodos para resolver problemas de ordem ambiental, valorizando a relação entre a sociedade e a natureza (MEDINA, 1997; GONÇALVES; REGALADO, 2007). O modo como as pessoas percebem o meio natural, influencia o modo como pensam, agem e expressam emoções com relação aos animais. Essa relação pode ser influenciada por diversos fatores, como: abundância do animal no local, ideia de sujeira ou limpeza, crenças, associação a doenças, noções de fragilidade ou resistência do animal, benefícios ou prejuízos, aparência entre vários outros (DREWS, 2002; BUSS et al., 2007).

Em Campo Grande, capital do Mato Grosso do Sul, existem as ararascanindé (Ara ararauna), que devido as ações antrópicas ocorridas no interior do Estado, no final da década de 90, deixaram a zona rural e vieram para cidade, onde encontraram grande diversidade de árvores frutíferas para se alimentarem e, posteriormente, locais para se reproduzirem, de forma que acabaram residentes na cidade (GUEDES, 2012; BARBOSA, 2015). As ararascanindé são conhecidas como arara-de-barriga-amarela e as vezes confundida com as araras azuis. Apresentam penas de coloração azul nas partes superior do corpo, amarelas nas inferiores, negras na garganta e verde na fronte, sua face é branca com fileiras de penas pretas (SICK, 1997).

Devido ao grande número de indivíduos de araras observados na cidade, Campo Grande ficou conhecida como capital das araras e, em 2015, a Lei Municipal $n^{\circ} 5.651$, instituiu a arara-canindé como ave símbolo da cidade. Essa lei indica que o Poder Executivo, através de seus órgãos competentes, deverá promover campanhas com o objetivo de difundir a importância da avifauna para a conservação dos ambientes naturais e da biodiversidade, desenvolvendo a economia e o turismo do município (DIOGRANDE, 2015). Portanto, este trabalho teve como objetivo analisar a percepção dos moradores sobre as araras-canindé (Ara ararauna) na área urbana de Campo Grande.

Revbea, São Paulo, V. 14, № 2: 277-294, 2019. 


\section{Material e Métodos}

\section{Área de estudo}

O trabalho foi realizado em Campo Grande, capital do estado de Mato Grosso do Sul, localizado na região centro oeste do Brasil (Figura 1). Apresenta uma área de $8.092,951 \mathrm{~km}^{2}$ e uma população estimada para 2017 de 874,210 habitantes (IBGE, 2016; PLANURB, 2017). A cidade de Campo Grande possui diversas áreas verdes como parques, reservas, manchas de buritizais, avenidas com mata ciliares, o que a torna uma das capitais mais arborizadas do país. Essas áreas tornaram-se importantes para a conservação das variadas espécies que nelas habitam, assim como as araras (BARBOSA, 2015).

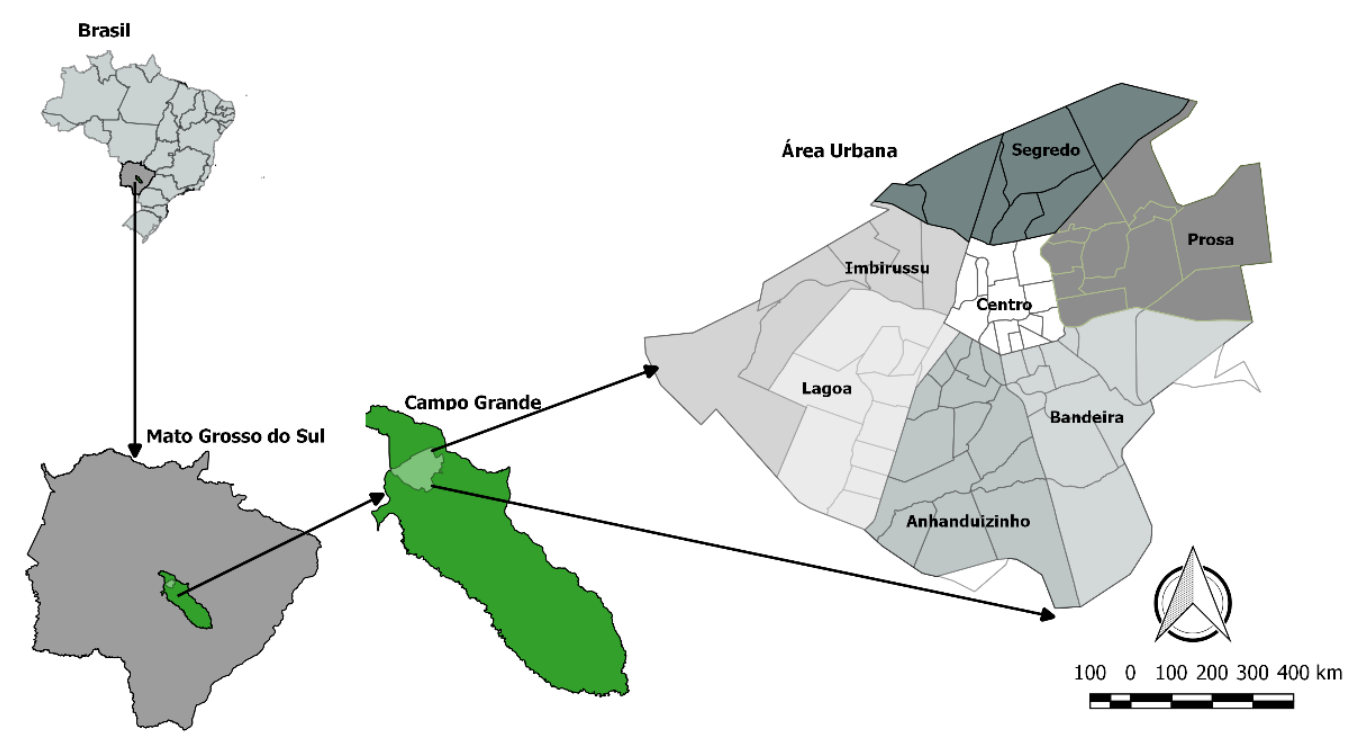

Figura 1: Mapa do estado de Mato Grosso do Sul, ressaltando a cidade de Campo Grande e sua área urbana. Fonte: Elaborado pelos autores.

\section{Coleta de dados}

Foi aplicado um questionário de abordagem qualiquantitativa, dividido em duas partes, a primeira com perguntas relacionada ao perfil do entrevistado e a segunda com questões de percepção, importância e conservação da araracanindé. Os dados foram coletados no ano de 2017 a 2018 para uma amostra de 423 indivíduos, que foram escolhidos e abordados aleatoriamente nas sete regiões que compõem a área urbana de Campo Grande. Os questionários foram aplicados durante visitas às residências e comércios das regiões e por redes sociais. 
O tamanho da amostra foi determinado a partir do método de amostragem estabelecido por Fonseca e Martins (2006) e de acordo com a equação (1). Para determinar a amostragem de cada região foi utilizado regra de três simples (Tabela 1 ).

$$
n=\frac{z^{2} p q N}{(N-1) e^{2}+z^{2} p q}
$$

Onde = tamanho da amostra; = valor associado ao nível de confiança de $95 \%$ $(z=1,96) ;=$ tamanho da população; = probabilidade de sucesso de hipótese $(50 \%$, pior caso, maior amostra); = probabilidade de fracasso da hipótese $(50 \%)$ e $=$ margem de erro $(5 \%)$.

Tabela 1: Número de questionários para cada região da cidade de Campo Grande, Mato

\begin{tabular}{cccc}
\hline \multicolumn{3}{c}{ Grosso do Sul. } \\
\hline Região & População & $\begin{array}{c}\mathbf{N}^{\circ} \text { questionários por } \\
\text { região }\end{array}$ & $\begin{array}{c}\mathbf{N}^{\circ} \text { questionários } \\
\text { aplicados }\end{array}$ \\
\hline Segredo & 108.962 & 56 & 56 \\
Prosa & 82.328 & 43 & 48 \\
Imbirussu & 98.752 & 51 & 51 \\
Lagoa & 114.447 & 59 & 59 \\
Anhanduízinho & 185.558 & 96 & 97 \\
Bandeira & 113.118 & 58 & 58 \\
Centro & 71.037 & 37 & 54 \\
\hline Total de habitantes & 774.202 & 400 & 423
\end{tabular}

Fonte: PLANURB (2017).

Para a realização da pesquisa foi solicitado autorização do Comitê de Ética de Pesquisa com Seres Humanos - CAAE: 70280317.0.0000.5161. Para a participação na pesquisa foi necessário que os moradores assinassem 0 Termo de Consentimento Livre e Esclarecido. A participação foi voluntária, e os questionários foram entregues para preenchimento ao morador com idade superior a 18 anos.

\section{Análise dos dados}

Para analisar os dados foi utilizado o software Sphinx Léxica 5.0, onde, os dados passaram por análise univariada, que descrevia o perfil dos entrevistados e análises bivariadas, onde, foram feitos cruzamentos de informações para verificar a percepção. O nível de associação entre as variáveis cruzadas foi feito por meio do teste Qui-quadrado $\left(X^{2}\right)$. (FREITAS e MOSCAROLA, 2000; FREITAS et al., 2002). Algumas questões foram elaboradas utilizando escalas de Likert, variando de 1 a 7 , onde 1 significa nenhuma importância/totalmente contra, até 7 muita importância/totalmente a favor, metodologia adaptada de Melo et al., 2016, as quais foram avaliadas pela análise fatorial. 


\section{Análise Fatorial}

Procedeu-se a análise fatorial dos dados estatísticos, com a função principal de reduzir o número original de variáveis (atributos) do bloco de questões em escala de Likert presente no questionário aplicado, pois, são questões que possuem a mesma natureza, de forma que os fatores independentes extraídos pudessem explicar, de forma simples e reduzida, as variáveis originais agrupadas. O tamanho da amostra obedeceu ao critério recomendado por Malhotra (2001) e Hair et al. (2009), de cinco observações por variável, pois, foram aplicados 423 questionários. Ainda, segundo Hair et al. (2009), a matriz de dados deve apresentar, um nível de significância menor ou igual a $5 \%$ para a matriz de correlações, condições suficientes para justificar a aplicação da análise fatorial. Foi utilizado o teste Kaiser-Meyer-Olkin de adequação da amostra (KMO), para comparar as correlações simples com as correlações parciais. Segundo Malhotra (2001) valores das correlações parciais entre 0,5 e 1 para a matriz toda ou para uma variável individual dá um indicativo de uma apropriada análise fatorial. O teste de esfericidade de Bartlett, foi utilizado para verificar se a matriz de correlação simples é próxima ou não da matriz identidade. Para que o modelo da análise fatorial possa ser usado, o teste de Bartlett deve rejeitar a hipótese nula.

A próxima etapa foi o da extração dos fatores, em que pode ser utilizado o método de análise de componentes principais com matriz de correlação. A obtenção da matriz das comunalidades é importante para a análise fatorial, pois, representa o total de variância que uma variável original compartilha com todas as outras variáveis incluídas na análise do mesmo fator. Uma variável com valor de comunalidade menor do que 0,5 tem potencial insuficiente de indicar uma boa explicação, portanto, devem ser eliminadas (HAIR et al., 2009). Neste trabalho utilizou-se a rotação Varimax, em que os eixos de referências são rotacionados em torno da origem até que uma melhor posição na distribuição das cargas fatoriais das componentes principais fosse alcançada. O efeito da rotação da matriz fatorial é redistribuir a variância dos primeiros fatores para os últimos, com o objetivo de atingir um padrão fatorial mais simples e fácil de ser interpretado. Variáveis cujas diferenças entre as cargas fatoriais entre dois fatores são menores do que $10 \%$, ou próximas a esse valor, devem ser eliminadas, com a reaplicação do processo (HAIR et al., 2009).

\section{Resultados e Discussão}

Entre os entrevistados, $171(40,4 \%)$ eram do sexo masculino e 252 $(59,6 \%)$ do sexo feminino, dados que seguem a proporção estimada no censo realizado pelo IBGE em 2010, onde, Campo Grande tinha uma população de 786,797 habitantes, 81.333 homens e 405.464 mulheres (PLANURB, 2017 IBGE, 2016). Ao observar o censo demográfico de 2010 para o Brasil, a razão de sexo ( $\mathrm{n}^{\circ}$ de homens para 100 mulheres) é de 93 a 97 e a idade mediana da população é de 29 anos (IBGE, 2016), esses dados diferem do encontrado na pesquisa para Campo Grande. A idade dos entrevistados variou de 18 a 86

revista brasileira educação ambiental 
anos, sendo que as faixas etárias com maior número de representantes foram as com menos de 30 anos e de 30 a 40 anos. Essas faixas etárias são semelhantes ao registrado por Melo et al. (2016), que analisou a percepção e valoração ambiental do Parque Estadual Matas do Segredo em Campo Grande, onde, obteve $55,3 \%$ dos participantes com faixa etária de 20 a 30 anos e $21,5 \%$ de 31 a 40 anos. Isso foi descrito por Mello et al. (2015), para o estudo sobre "Percepção dos usuários do parque ecológico "João Domingos Coelho" Assis (SP), quanto ao meio ambiente e aves", onde a faixa etária prioritariamente encontrada, estava entre 21 e 40 anos (53,7\%) dos usuários.

Quanto à escolaridade dos entrevistados a maioria possuem ensino superior completo (36\%), seguido por superior incompleto (26\%). Com ensino médio completo (19\%) e com ensino médio incompleto (7\%), os $12 \%$ restante ensino fundamental completo e incompleto. Ao cruzar os dados da idade e grau de escolaridade foi observado que os entrevistados com maior escolaridade estavam entre as faixas etárias com menos de 40 anos. Esses dados se assemelham com os dados do censo do IBGE (2016), onde, a faixa etária de 20 a 39 anos de idade, possui $59 \%$ de pessoas com grau de escolaridade de nível médio completo a ensino superior completo.

Em relação ao interesse por questões ambientais, 48,5\% (205) se disseram muito interessados, $41,4 \%$ (175) são razoavelmente interessados, $8 \%$ (34) tem pouco interesse e 1,9\% (8) não tem nenhum interesse. Ao analisar a relação idade $x$ interesse por questões ambientais, não houve dependência significativa $\left(X^{2}=10,89, \mathrm{gl}=18,1-\mathrm{p}=10,10 \%\right)$, ou seja, a idade dos entrevistados não influência os interesses por questões ambientais. Em todas as faixas etárias o resultado foi positivo, totalizando $89,9 \%$ em muito ou razoavelmente interessado, porém, ao cruzar os dados escolaridade $x$ interesse por questões ambientais, houve uma dependência muito significativa $\left(X^{2}=72,53 ; \mathrm{gl}=15,1\right.$ e $\left.\mathrm{p}=>999,99 \%\right)$, dos 205 entrevistados que se dizem muito interessado, $110(53,7 \%)$ possuem o ensino superior completo (Tabela 2).

Sobre a percepção da importância da arara-canindé e a conservação da espécie na área urbana, foram feitas nove perguntas em escala de Likert. Foram relacionados o mínimo valor e o máximo valor atribuídos em cada questão e calculadas as médias aritméticas, os desvios padrão e os coeficientes de variação para facilitar as análises e servirem como indicadores (Tabela 3). Observa-se que, excluindo o atributo 8, cuja média foi 4,17, indicando que os entrevistados permaneceram neutros nas respostas a essa questão, ou talvez, não a entenderam com clareza. As respostas aos demais atributos chamaram a atenção em virtude de que as notas se aproximaram da nota máxima 7 , isto é, um julgamento de muita importância aos atributos contidos nessas questões. 
Tabela 2: Analise dos dados: Escolaridade $X$ Interesse por questões ambientais de oito regiões (Segredo, Prosa, Imbirussu, Lagoa, Anhanduízinho, Bandeira e Centro) de Campo Grande, Mato Grosso do Sul.

\begin{tabular}{lccccc}
\hline Escolaridade/Interesse & $\begin{array}{c}\text { Muito } \\
\text { interessado }\end{array}$ & $\begin{array}{c}\text { Razoavelmente } \\
\text { interessados }\end{array}$ & $\begin{array}{c}\text { Pouco } \\
\text { interessado }\end{array}$ & $\begin{array}{c}\text { Nenhum } \\
\text { interesse }\end{array}$ & Total \\
\hline $\begin{array}{l}\text { Ens. Fundamental } \\
\text { Incompleto }\end{array}$ & 14 & 12 & 5 & 1 & 32 \\
$\begin{array}{l}\text { Ens. Fundamental } \\
\text { Completo }\end{array}$ & 4 & 12 & 0 & 0 & 16 \\
Ens. Médio Incompleto & 10 & 20 & 2 & 0 & 32 \\
Ens. Médio Completo & 21 & 49 & 7 & 2 & 79 \\
Ens. Superior Incompleto & 46 & 52 & 12 & 2 & 112 \\
Ens. Superior Completo & 110 & 30 & 8 & 3 & 151 \\
\hline TOTAL & 205 & 175 & 34 & 8 & 422 \\
\hline
\end{tabular}

Fonte: Dados da pesquisa.

Tabela 3: Indicadores (mínimo, máximo, média, desvio padrão e coeficiente de variação) sobre os atributos da importância da conservação do ambiente na cidade de Campo Grande, propiciando habitat ideal à arara-canindé, em 2018.

\begin{tabular}{lccccc}
\hline Atributo & Mín & Máx & Méd & DP & CV(\%) \\
\hline 1.Conservar a vegetação na área urbana. & 1 & 7 & 6,79 & 0,61 & 9,04 \\
2.Conservar toda espécie de animais. & 5 & 7 & 6,90 & 0,35 & 5,13 \\
3.Plantar arvores frutíferas. & 2 & 7 & 6,79 & 0,60 & 8,85 \\
4.Incentivar a observação de aves. & 1 & 7 & 6,47 & 0,91 & 14,11 \\
5.Combater o tráfico de animais silvestres. & 4 & 7 & 6,94 & 0,33 & 4,78 \\
6.Presença das araras na cidade. & 1 & 7 & 6,60 & 0,88 & 13,27 \\
7.As araras dão visibilidade à cidade. & 3 & 7 & 6,57 & 0,84 & 12,83 \\
$\begin{array}{l}\text { 8.Praticar ações para a preservação das áreas } \\
\text { verdes urbanas. }\end{array}$ & 1 & 7 & 4,17 & 2,29 & 54,99 \\
9.Se preocupa com a preservação das araras na & 1 & 7 & 6,15 & 1,36 & 22,03 \\
área urbana de Campo Grande. & & & & & \\
\hline
\end{tabular}

*1=pouco importante até 7 = muito importante.

Ainda, relativo à Tabela 3 , observa-se que os desvios padrão da maioria dos atributos estão muito baixos, inferiores a 15\%, demonstrando bastante homogeneidade nas respostas. O coeficiente de variação da questão 8 foi de $54,99 \%$, mostrando a grande heterogeneidade das respostas, confirmando o que foi dito anteriormente, que o entrevistado não deve ter entendido bem a questão, ou se sentido impotente da consecução da mesma. A questão 9 também teve um coeficiente de variação de $22,03 \%$, mostrando uma média homogeneidade, o que é razoável estatisticamente.

A maioria ( $n=364$ ) dos entrevistados responderam que acham muito importante a conservação da biodiversidade urbana. Para Villar et al., 2008 não se pode excluir a possibilidade de que parte das respostas não deve refletir as 
práticas executadas, pois uma parcela dos indivíduos prefere negar a sua condição por considerar estas atitudes incorretas ou porque habitualmente não pratiquem essas ações, porém, em Campo Grande a participação da população na conservação da arara-canindé é muito importante, uma vez que a maioria dos ninhos se localizam em residências. Os quintais urbanos são importantes instrumento de sensibilização e incentivo à percepção das pessoas. Algumas ações realizadas nos quintais além de proporcionar o bemestar ao morador através do contato com a natureza, servem como abrigo e complementam a alimentação dos animais através das árvores frutíferas plantadas (BARBOSA, 2018).

Alguns autores (SCHUCH, 2006; BRUN et al., 2007; BERMAN et al., 2008) relatam que as áreas verdes nos centros urbanos, proporcionam uma qualidade de vida melhor, agindo, diretamente na saúde mental e física da população, valorizam os ambientes ao redor, além dos vários serviços ecossistêmicos prestados como, amenização do clima, controle da poluição do ar e local de refúgio e proteção para fauna. Apesar de saber que as áreas verdes são de grande importância, quando, perguntado aos entrevistados sobre a prática de ações que ajudem na conservação de áreas verdes urbanas, $27 \%$ relatou não praticar nenhum tipo de ação. Apesar disso, 76,6\% disseram que se preocupam com a conservação dessas áreas e 99,1\% apontaram que é responsabilidade de todos, tanto dos governantes como da população, a conservação da fauna e das áreas verdes urbanas. Em relação a não praticar ações nas áreas verdes urbanas, muitos entrevistados relataram que essas áreas são de domínio do poder público e que seria necessário, autorização para se praticar qualquer tipo de ação, porém, os moradores colaboram com ações em seus quintais, bairros e estão sempre atentos e cobrando o poder público para manter as áreas verdes conservadas.

Os índices de correlações, bem como os níveis de significâncias correspondentes entre todas as variáveis atingiram níveis favoráveis à aplicação de análise fatorial. O determinante da matriz das variáveis foi de 0,218, também favorável à continuidade da aplicação de análise fatorial. Prosseguindo com os testes da análise fatorial, o teste de Kaiser-Meyer-Olkin $(\mathrm{KMO})=0,763$, que indica uma análise fatorial apropriada, o teste de esfericidade de Bartlett (para valor menor do que 0,01 deve-se prosseguir na análise fatorial) (Quadro 1).

Quadro1: Testes KMO e de Bartlett de adequação da amostragem.

\begin{tabular}{|l|l|l|}
\hline \multicolumn{2}{|l|}{ Medida Kaiser-Meyer-Olkin de adequação de amostragem. } & 0,763 \\
\hline \multirow{3}{*}{ Teste de esfericidade de Bartlett } & Aproximação Qui-quadrado & 581,336 \\
\cline { 2 - 3 } & Gl & 28,000 \\
\cline { 2 - 3 } & p. & 0,000 \\
\hline
\end{tabular}


Com relação às medidas de comunalidades, na extração, todas as variáveis apresentaram valores maiores do que 0,5 , portanto, todas as variáveis permaneceram no teste de análise fatorial (Quadro 2).

Quadro 2: Comunalidades das variáveis inicial e após a extração.

\begin{tabular}{|l|l|l|}
\hline Variáveis & Inicial & Extração \\
\hline Conservar a vegetação na área urbana & 1,000 & 0,755 \\
\hline Conservar toda espécie de animais & 1,000 & 0,691 \\
\hline Plantar arvores frutíferas & 1,000 & 0,884 \\
\hline Incentivar a observação de aves & 1,000 & 0,622 \\
\hline Combater o tráfico de animais silvestres & 1,000 & 0,816 \\
\hline As araras são importantes para a cidade & 1,000 & 0,778 \\
\hline As araras geram visibilidade para a cidade & 1,000 & 0,795 \\
\hline Pratica ações que ajudem na preservação das áreas verdes urbanas? & 1,000 & 0,818 \\
\hline $\begin{array}{l}\text { Se preocupa com a preservação das araras na área urbana de Campo } \\
\text { Grande }\end{array}$ & 1,000 & 0,674 \\
\hline
\end{tabular}

Depois de atendido ao critério das comunalidades, pode-se extrair quatro fatores que resumem as nove variáveis iniciais em estudo. Com isso, pode-se obter uma redução de mais de $50 \%$ do número de variáveis originais, que eram nove, para apenas quatro. No Quadro 3 estão apresentados os autovalores e as variâncias dos fatores que influenciaram na percepção. Observa-se que os quatro fatores em negrito, explicam $67,50 \%$ da percepção do habitante, sobre a conservação da arara-canindé na área urbana da cidade.

Quadro 3: Autovalores iniciais, variância explicada e acumulada com extração de quatro fatores que mais influenciam na importância da conservação do meio ambiente na cidade de Campo Grande.

\begin{tabular}{|c|c|c|c|}
\hline \multirow{2}{*}{ Fatores } & \multicolumn{3}{|c|}{ Valores próprios iniciais } \\
\cline { 2 - 4 } & $\begin{array}{c}\text { \% de } \\
\text { variância }\end{array}$ & \% cumulativa \\
\hline $\mathbf{1}$ & $\mathbf{2 , 8 2 2}$ & $\mathbf{3 1 , 3 5 9}$ & $\mathbf{3 1 , 3 5 9}$ \\
\hline $\mathbf{2}$ & $\mathbf{1 , 2 5 6}$ & $\mathbf{1 3 , 9 5 6}$ & $\mathbf{4 5 , 3 1 4}$ \\
\hline $\mathbf{3}$ & $\mathbf{1 , 1 6 4}$ & $\mathbf{1 2 , 9 3 1}$ & $\mathbf{5 8 , 2 4 6}$ \\
\hline $\mathbf{4}$ & $\mathbf{0 , 8 3 3}$ & $\mathbf{9 , 2 5 5}$ & $\mathbf{6 7 , 5 0 1}$ \\
\hline $\mathbf{5}$ & 0,759 & 8,428 & 75,929 \\
\hline 6 & 0,624 & 6,934 & 82,863 \\
\hline 7 & 0,582 & 6,472 & 89,335 \\
\hline 8 & 0,502 & 5,574 & 94,909 \\
\hline 9 & 0,458 & 5,091 & 100,000 \\
\hline
\end{tabular}


O Quadro 4 apresenta a matriz fatorial rotacionada (no sentido de facilitar a distribuição das variâncias explicadas pelas variáveis), que influenciam na decisão da importância da conservação da arara-canindé em Campo Grande.

Quadro 4: Matriz fatorial rotacionada das variáveis que influenciam na decisão de conservação da arara-canindé na zona urbana de Campo Grande, em 2018.

\begin{tabular}{|c|c|c|c|c|}
\hline \multirow{2}{*}{ Variáveis } & \multicolumn{4}{|c|}{ Fator } \\
\hline & 1 & 2 & 3 & 4 \\
\hline As araras são importantes para a cidade & 0,644 & & & \\
\hline $\begin{array}{l}\text { Pratica ações que ajudem na preservação das áreas } \\
\text { verdes urbanas }\end{array}$ & 0,762 & & & \\
\hline $\begin{array}{l}\text { Se preocupa com a preservação das araras na área } \\
\text { urbana de Campo Grande }\end{array}$ & 0,788 & & & \\
\hline Combater o tráfico de animais silvestres & & 0,788 & & \\
\hline Conservar a vegetação na área urbana & & 0,580 & & \\
\hline Conservar toda espécie de animais & & 0,814 & & \\
\hline Plantar arvores frutíferas & & & 0,914 & \\
\hline Incentivar a observação de aves & & & 0,517 & \\
\hline As araras geram visibilidade para a cidade & & & & 0,796 \\
\hline
\end{tabular}

A partir dos dados obtidos com a matriz fatorial rotacionada, pode-se nomear os quatro fatores de acordo com cada característica dos atributos da percepção dos habitantes de Campo Grande, sobre a conservação da araracanindé na área urbana.

No primeiro fator têm-se as variáveis "As araras são importantes para a cidade", "conservação das áreas verdes na cidade", "conservação das araras na cidade". Diante disso, esse fator pode ser nomeado como "Conservação das araras". A conservação da arara-canindé na área urbana de Campo Grande foi considerada importante para todos os moradores. São aves coloridas e carismáticas que encantam e chamam a atenção, fazem com que as pessoas voltem seus olhares, tanto para a cidade, como também para a necessidade de se praticar à conservação do ambiente, visando não só a qualidade de vida das araras como também das outras espécies (INGOLD, 1995; GUEDES, 2012).

No segundo fator há um agrupamento das variáveis "combater o tráfico de animais silvestres", "conservar a vegetação na área urbana" e "conservar todas as espécies de animais", podendo esse fator, diante dessas variáveis, ser nomeado como "Cuidados com os animais".

Revbea, São Paulo, V. 14, № 2: 277-294, 2019. 
O homem necessita estar em contato com a natureza, pois, existe uma ligação emocional entre eles que foi adquirida a milhões de anos atrás, esta é desencadeada pela ativação dos canais sensitivos e afetivos, que pode ocorrer por meio da observação da beleza, dos detalhes de comportamento e morfologia, ou pela vocalização das aves (INGOLD, 1995). Assim, sabe-se que a conservação é retratada na escola, desde o ensino fundamental até o ensino superior, pois, o ser humano é o maior responsável pela conservação das espécies na terra. A preocupação do homem com a conservação da biodiversidade é relatada em vários estudos como Wilson (1989); Constanza et al. (1997); Coutinho (2001); Andrade et al. (2009).

O terceiro fator apresentou duas variáveis, "plantar árvores frutíferas" e "incentivar a observação das aves", podendo esse fator ser nomeado como "Conservação e lazer". Essa é uma questão que procura mostrar os benefícios que a conservação da arara-canindé pode trazer ao habitante de Campo Grande. Com o plantio de árvores frutíferas na cidade para consumo dos animais e, por que não, dos habitantes, pode-se propiciar a observação das aves e outros animais, como um lazer para a população e incentivo a conservação das áreas verdes, além disso, as árvores auxiliam na regulação térmica, proporcionando maior conforto térmico.

Campo Grande é uma capital em constate crescimento e com alto grau de urbanização, possui 74 bairros divididos em sete regiões (PLANURB, 2017), mas que vem conseguindo se desenvolver com a manutenção de áreas verdes e outros ambientes naturais. Mesmo em constante crescimento, Campo Grande é considerada uma das capitais mais arborizadas do país (BARBOSA, 2015; GUEDES, 2012), segundo dados da PLANURB (2017), a cidade possui 124 espaços abertos para lazer como praças, parques, orla, reservas ecológicas entre outros. A Tabela 4 mostra os dados demográficos das sete regiões de Campo Grande, a classe social que predomina nas regiões é a classe C (PLANURB, 2017).

Tabela 4: Dados demográficos e rendimento das regiões de Campo Grande.

\begin{tabular}{lccccc}
\hline Região & População & Área (ha) & $\begin{array}{c}\text { Densidade } \\
\text { demográfica } \\
\text { (hab/ha) }\end{array}$ & $\begin{array}{c}\text { Rendimento } \\
\text { Médio mensal }\end{array}$ & $\begin{array}{c}\text { Renda } \\
\text { per capita }\end{array}$ \\
\hline Segredo & 108.962 & $4.497,50$ & 24,23 & 738,83 & 621,56 \\
Prosa & 82.328 & $5.565,46$ & 14,79 & $1.647,26$ & $1.417,55$ \\
Imbirussu & 98.752 & $5.742,91$ & 17,20 & 872,35 & 750,18 \\
Lagoa & 114.447 & $5.057,12$ & 22,63 & 764,88 & 648,49 \\
Anhanduízinho & 185.558 & $6.192,03$ & 29,97 & 656,21 & 551,59 \\
Bandeira & 113.118 & $6.236,26$ & 18,14 & 985,33 & 845,62 \\
Centro & 71.037 & $2.011,50$ & 35,32 & $2.270,14$ & $2.067,94$ \\
\hline Campo Grande & $\mathbf{7 7 4 . 2 0 2}$ & $\mathbf{8 0 9 . 2 9 5}$ & $\mathbf{2 1 , 9 3}$ & $\mathbf{1 . 0 1 4 , 2 7}$ & $\mathbf{8 6 7 , 7 6}$ \\
\hline
\end{tabular}

Fonte: PLANURB (2017) - Perfil Socioeconômico de Campo Grande. 
O mapa da exclusão social de Campo Grande, mostra que as famílias mais carentes se concentram nas áreas periféricas da capital. Se caracterizam por serem desestruturadas, ou seja, não possuem uma estrutura parental representada por um pai, uma mãe e o(s) filho(s), os pais permanecem fora de casa a maior parte do tempo. O baixo poder aquisitivo remete à pouca aquisição de livros, computadores, cursos, lazer e ausência de cuidado integral (SAUER et al., 2012). Assim sendo, é preciso olhar com mais atenção para essas regiões carentes e levar a educação ambiental com mais frequência até as crianças e adultos.

Observa-se que a região do Anhanduizinho é a mais populosa e com a menor renda per capita. Quando relacionado as variáveis região x prática de ações que ajudem na conservação das áreas verdes urbana (Tabela 5), a dependência é significativa, onde, $X^{2}=13,73, g l=6,1-p=96,72 \%$. Essa região, possui o maior número de entrevistados que não praticam ações para ajudar a conservar as áreas verdes. Por outro lado, a região do Anhanduizinho e na região do Bandeira, existem quatro parques lineares, um parque ecológico, uma estação ecológica e uma RPPN (Reserva Particular do Patrimônio Natural) que são fundamentais para a manutenção da biodiversidade urbana, valorizam as regiões e melhoram a qualidade de vida dos habitantes (PLANURB, 2017).

O Instituto Arara Azul, através do Projeto Aves Urbanas - Araras na Cidade, realiza palestras e oficinas em escolas e universidades, publica matérias em artigos, revistas, jornais, programas de televisão e também realiza o turismo de observação, pois acredita que levando a educação ambiental, pode-se despertar a percepção, a curiosidade, a compaixão e o amor de cada indivíduo, para que este desenvolva atitudes positivas.

Tabela 5: Cruzamento dos dados: Região x Prática de ações que ajudem na conservação das áreas verdes urbanas de Campo Grande, Mato Grosso do Sul.

\begin{tabular}{lcccc}
\hline $\begin{array}{c}\text { Região/Ações que } \\
\text { ajudem na conservação }\end{array}$ & $\mathbf{1}$ & $\mathbf{7}$ & Total & (\%) \\
& (Não pratica) & (Sempre pratica) & & 43 \\
\hline Centro & 10 & 13 & 23 & 5 \\
Segredo & 15 & 16 & 31 & 30 \\
Prosa & 7 & 16 & 23 & 48 \\
Imbirussu & 13 & 14 & 27 & 61 \\
Lagoa & 21 & 13 & 34 & 68 \\
Bandeira & 17 & 8 & 25 & 68 \\
Anhanduizinho & 31 & 14 & 45 & \\
\hline Total & 114 & 94 & 208 & \\
\hline
\end{tabular}

Fonte: Dados da pesquisa. 
Em Campo grande, as araras-canindé foram eleitas ave símbolo da cidade e a Figura 2 nos mostra que os ninhos ocupados por elas estão espalhados por toda a área urbana. No total são 159 ninhos cadastrados pelo Projeto Aves Urbanas - Araras na Cidade até dezembro de 2017.

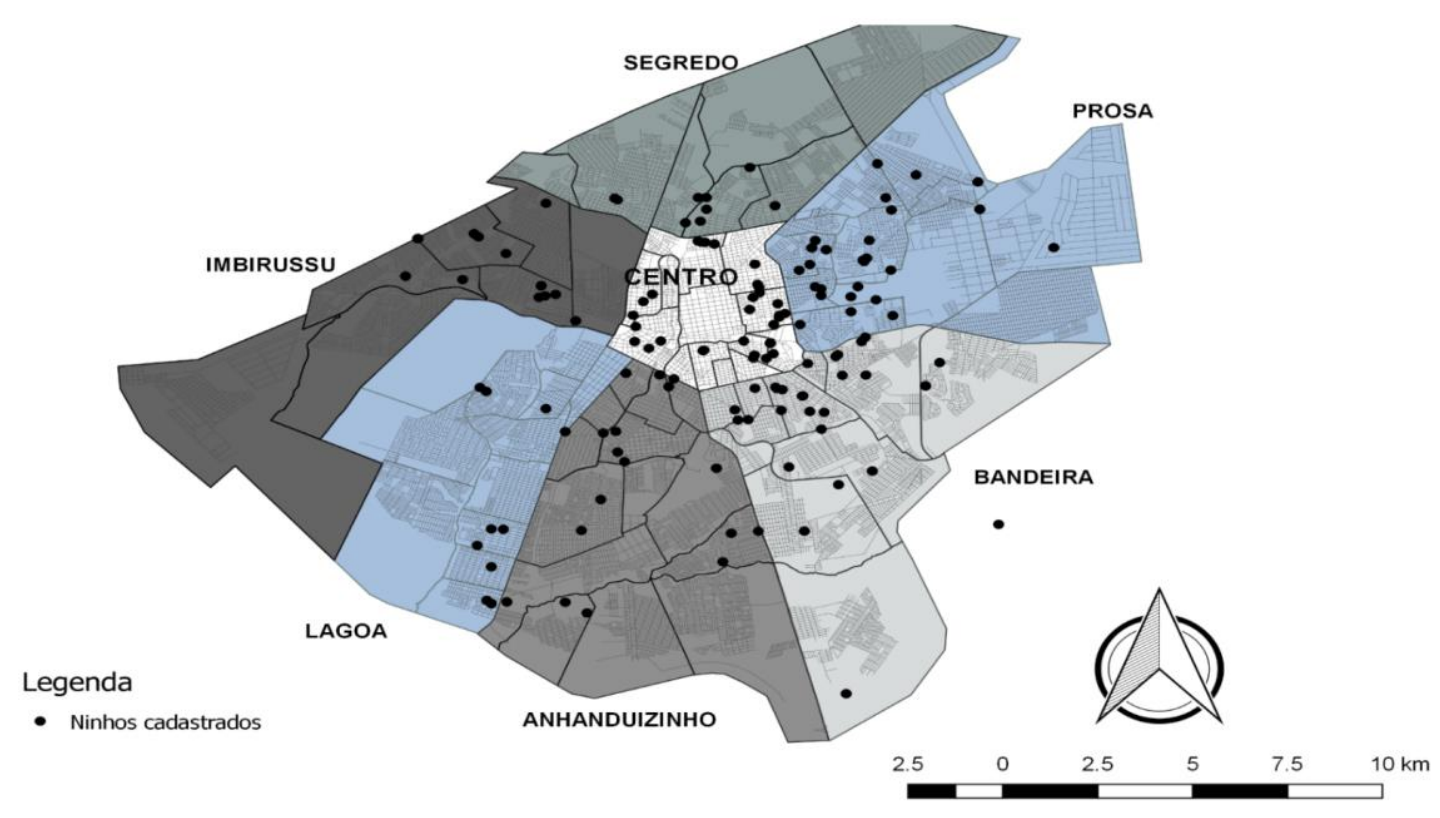

Figura 2: Ninhos cadastrados (ponto preto) das araras-canindé (Ara ararauna) nas sete regiões do perímetro urbano de Campo Grande, Mato Grosso do Sul $(n=159)$ até dezembro de 2017.

Fonte: Instituto Arara Azul.

No quarto fator ficou somente uma variável "As araras geram visibilidade para a cidade", podendo o fator ser representado pelo nome "Visibilidade para a cidade". Esse fator é tão importante, que, em alguns casos, a presença de um animal pode caracterizar turisticamente uma cidade. Nesse caso, a cidade de Campo Grande tem ostentado o "slogan" - Cidade ou Capital das Araras.

Devido à grande importância e ao reconhecimento da espécie na cidade, foi criada a Lei Municipal $n^{\circ} 5651$ que instituiu a arara-canindé como ave símbolo de Campo Grande. Pode-se constatar a importância das araras, também, através da utilização da imagem dessa espécie em muros de residências, propagandas, assim como, em diversas reportagens, citando Campo Grande como a capital das araras (Figura 3). 

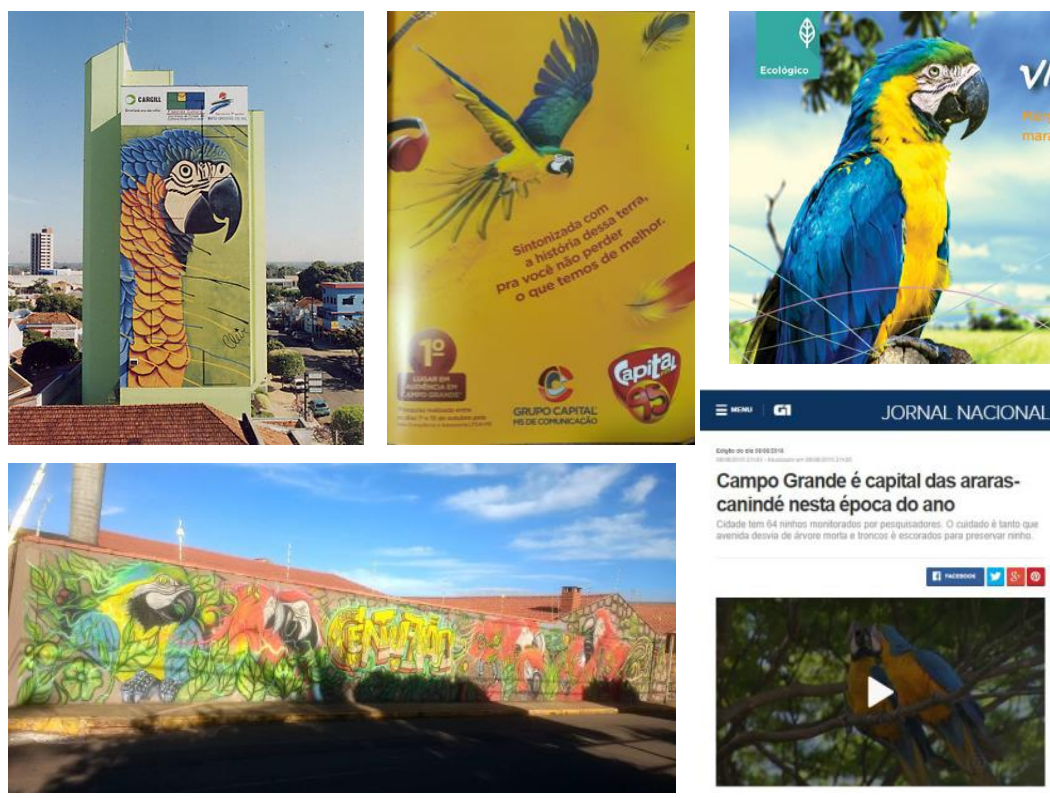

Figura 3: Fotos e propagandas retratando as araras-canindé e sua importância.

No total, $93,3 \%$ dos entrevistados responderam que já pararam para observar as araras e 6,4\% disseram que não. Os sites wikiaves e e-bird, mostram que as pessoas gostam de observar e fazer registros fotográficos das araras-canindé. Na cidade de Jardim, temos este mesmo exemplo, as pessoas se deslocam para a cidade para praticar o ecoturismo na RPPN Buraco das Araras, onde, fazem passeios em trilhas para a contemplação das ararasvermelhas que são residentes no local (MELO et al., 2018).

Os arquivos do Instituto Arara Azul, mostram que todos os anos, moradores e turistas procuram a instituição para conhecer e realizar turismo de observação com o Projeto Aves Urbanas - Araras na Cidade, que estuda a biologia reprodutiva da arara-canindé na área urbana de Campo Grande e, também, retratam a mobilização da população para a conservação da espécie (Figura 4). 

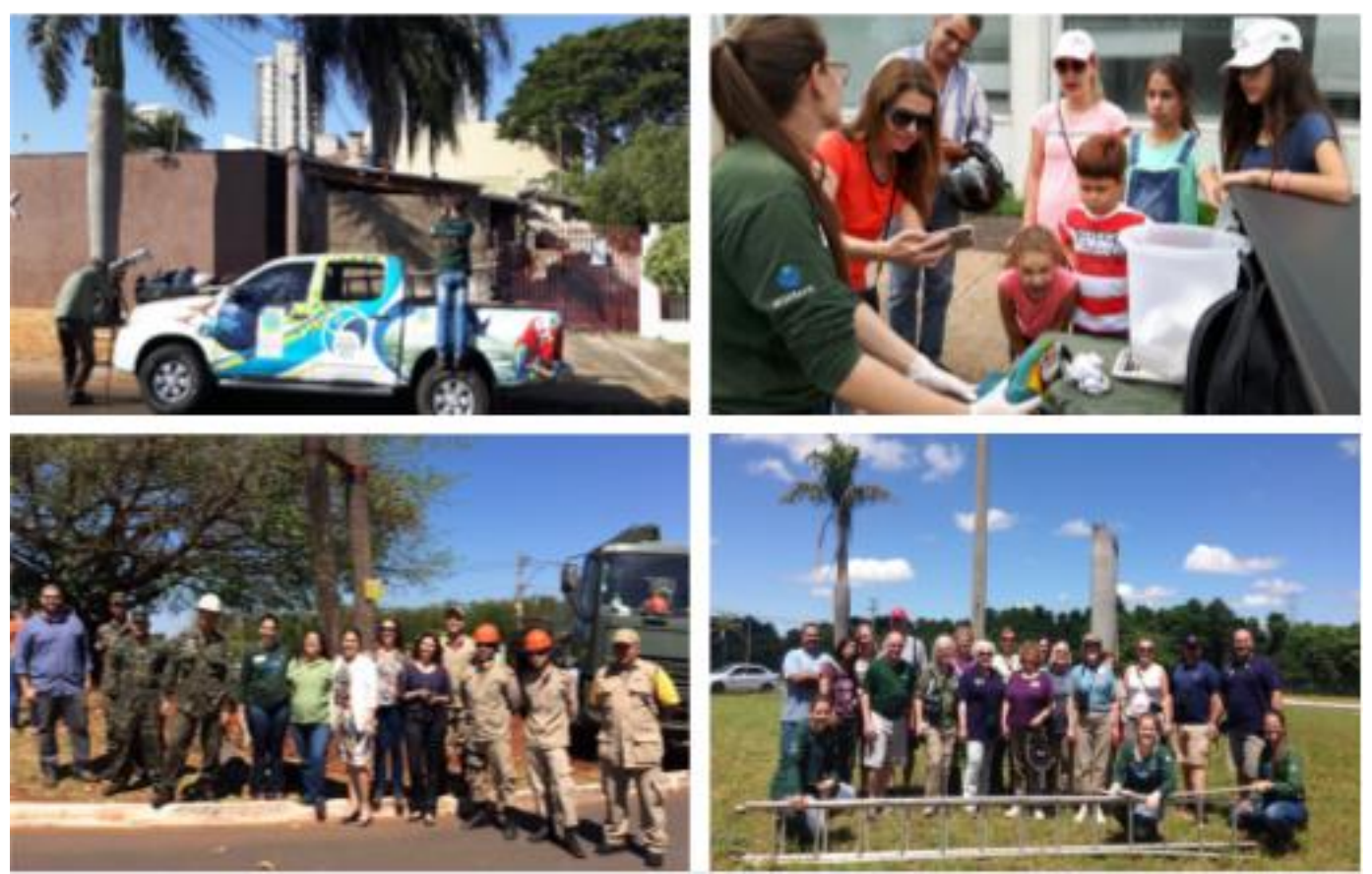

Figura 4: Fotos retratando moradores e turistas que praticaram o turismo de observação.

Quando perguntado ao entrevistado o que ele sentia ao ver uma arara, $52 \%$ sentiam felicidade, $43,3 \%$ sensação de bem-estar e 4,3\% disseram não sentir nada. Para os autores Andrade (1993); Hermy e Cornelis (2000); Clergeu et al. (2001); Toledo (2007) as aves possuem grande valor para o homem, elas transmitem inspiração, paz, tranquilidade e alegria, polinizam flores, disseminam sementes e são bioindicadores da qualidade ambiental. Para Wilson (1997) a partir do momento que o homem passou a viver em centros urbanos, ele sentiu a necessidade de estar em contato com a natureza para vivenciar em plenitude os seus sentidos e instintos naturais, pois, essa relação se dá através da história genética existente há milhões de anos e não é possível apagá-la.

\section{Conclusões}

Os moradores, em sua maioria, têm interesse por questões ambientais, percebem a importância da biodiversidade urbana e dos serviços ecossistêmicos que ela fornece, sabem que o homem faz parte deste meio e que a falta de conservação reflete na sobrevivência dos seres vivos, todavia, nem todos praticam ações que ajudem na conservação das áreas verdes urbanas, mas muitos relataram que praticam ações em casa ou no bairro.

Os resultados obtidos nos mostram que os moradores consideram as araras-canindé importantes e que elas geram muita visibilidade para a cidade de Campo Grande, contudo, fica evidente que há a necessidade de se trabalhar a educação ambiental, utilizando-a como ferramenta para difundir conhecimento, envolver a população na conservação da biodiversidade e ampliar a compreensão de cidadania. 


\section{Agradecimentos}

Agradeço a todos que apoiaram e ajudaram para que este trabalho fosse realizado. A equipe do Projeto Aves Urbanas - Araras na Cidade, Sabrina Appel, Luiz Guilherme Dervalho, Eliza Mense e Eveline Guedes. Ao apoio logístico e técnico do Instituto Arara Azul e da Fundação Toyota do Brasil, à Universidade Anhanguera-Uniderp e à CAPES pela concessão de bolsa de mestrado. Aos moradores de Campo Grande que cederam um pouco do seu tempo para responder ao questionário e ajudar na realização desta pesquisa.

\section{Referências}

ANDRADE, M. A. A vida das aves: Introdução à biologia e conservação. Belo Horizonte: Editora Líttera Maciel, 1993. 160p.

BARBOSA, L. T. Avaliação do sucesso reprodutivo da arara-canindé (Ara ararauna - Psittacidae) e o desenvolvimento urbano de campo Grande, Mato Grosso do Sul. 2015. 60f. Dissertação (Mestrado em Meio Ambiente e Desenvolvimento Regional) - Universidade Anhanguera Uniderp. Campo Grande.

BARBOSA, L. T. Fatores que influenciam o sucesso reprodutivo da araracanindé (Ara ararauna) em Campo Grande, Mato Grosso do Sul. 2018. $121 f$. Tese (Doutorado em Meio Ambiente e Desenvolvimento Regional) Universidade Anhanguera Uniderp. Campo Grande.

BERMAN, M. G.; JONIDES, J.; KAPLAN, S. Os benefícios cognitivos da interação com a natureza. Ciência Psicológica, Montevidéu, Uruguai, v. 19, n. 12, p.1207-1212, 2008.

BRUN, F. G. K.; LINK, D.; BRUN, E. J. O emprego da arborização na manutenção da biodiversidade de fauna em áreas urbanas. Revista da Sociedade Brasileira de Arborização Urbana, Piracicaba, v. 2, n.1, p. 117127,2007

COSTANZA, R.; D'ARGE, R.; GROOT, R. S.; FARBER, S.; GRASSO, M.; HANNON, B.; LIMBURG, K.; NAEEM, S.; O'NEILL, R. V.; PARUELO, J.; RASKIN, R. G.; SUTTON, P.; VAN DEN BELT, M. The value of the world's ecosystem services and natural capital. Nature, Londres, v. 387, n. 6630, p. 253-260. 1997.

COUTINHO, P. O valor da biodiversidade. 2001. Disponível on-line: $<$ http://www.comciencia.br/reportagens/biodiversidade/bio12.html>. Acesso em: 22 junho 2017.

CLERGEAU, P.; JOKIMÄKI, J.; SAVARD, J-P. L. Are urban bird communities influenced by the bird diversity of adjacent landscapes?. Journal of applied ecology, Londres, v. 38, n. 5, p. 1122-1134, 2001.

DIOGRANDE. Lei n. 5.561, de 15 de junho de 2015. Institui a ave simbólica do município de Campo Grande-MS e dá outras providências. Diário Oficial de Campo Grande, Poder executivo, Campo Grande, MS, 16 jun. 2015. p. 1.

Revbea, São Paulo, V. 14, № 2: 277-294, 2019. 
DREWS, C. Attitudes, knowledge and wild animals as pets in Costa Rica. Anthrozoös, Oxford, v. 15, n. 2, p. 119-138, 2002.

FAGGIONATO, S. Percepção Ambiental. 2005. Disponível em: $<$ http://educar.sc.usp.br>. Acesso em 14 de fevereiro de 2018.

FERNANDES, R. S.; SOUZA, V. J.; PELISSARI, V. B.; FERNANDES, S. T. Uso da percepção ambiental como instrumento de gestão em aplicações ligadas às áreas educacional, social e ambiental. In: II Encontro Nacional de PósGraduação e Pesquisa em Ambiente e Sociedade, 2004, Indaiatuba. Anais... Indaiatuba: ANPPAS, 2004. p. 1-15.

FONSECA, J.S.; MARTINS, G.A. Curso de Estatística. São Paulo: Atlas. 1996. v. 6. 84p.

FREITAS, H., JANISSEK, R., MOSCAROLA, J., BAULAC, Y. Pesquisa interativa e novas tecnologias para coleta e análise de dados usando 0 Sphinx. Porto Alegre: Sphinx, 2002. 384p.

FREITAS, H.; MOSCAROLA, J. Análise de dados quantitativos e qualitativos: casos aplicados usando o Sphinx. Porto Alegre: Sphinx, 2000. $178 p$.

GONÇALVES, M. L. Q.; REGALADO, L. B. A relação entre o homem e o animal silvestre como uma questão de educação ambiental. Fórum ambiental da alta paulista, Tupã, v. 3, n. 1, p. 309-330, 2007.

GUEDES, N. M. R. Araras da Cidade. In: QUEVEDO, T. L. Araras da cidade Músicas do Mato. Campo Grande: Editora Alvorada, 2012. 160p.

HAIR Jr. J. F.; BLACK, W. C; BABIN, B. J.; ANDERSON, R. E.; TATHAM, R. L.; Análise Multivariada de Dados. 6ed. Porto Alegre: Bookman, 2009. 688p.

HERMY, M.; CORNELIS, J. Towards a monitoring method and a number of multifaceted and hierarchical biodiversity indicators for urban and suburban parks. Landscape and Urban Planning, Toronto, v. 49, n. 3-4, p. 149-162, 2000.

IBGE. Instituto Brasileiro de Geografia e Estatística 2016. Atlas Brasil 2013, apresenta o Índice de Desenvolvimento Humano Municipal. Disponível: $<$ http://www.ibge.gov.br/estadosat/temas.php?tema=idhm>. Acesso em $15 \mathrm{fev}$. 2017.

INGOLD, T. Humanidade e animalidade. Revista Brasileira de Ciências Sociais, $n^{\circ}$ 28, 1995. 39-52 p.

MALHOTRA, N. K. Pesquisa de Marketing: uma orientação aplicada. 4ed. Porto Alegre: Bookman,2001. 768p.

MEDINA, N. M. Breve histórico da Educação Ambiental. In: Pádua SM, Tabanez MF (orgs.). Educação Ambiental: caminhos trilhados no Brasil. Brasília-DF: Instituto de Pesquisas Ecológicas - IPÊ, 1997. p.257-269. 
MELAZO, G. C. Percepção ambiental e educação ambiental: uma reflexão sobre as relações interpessoais e ambientais no espaço urbano. Olhares \& Trilhas, Uberlândia, Ano VI, n. 6, p. 45-51, 2005.

MELLO, G. F.; RIBEIRO, A. I.; BONGIOVANNI, S. Percepção dos usuários do Parque Ecológico "João Domingos Coelho", Assis/SP, quanto ao meio ambiente e aves, antes e após a implantação de placas informativas da avifauna local. Revista Brasileira de Educação Ambiental (RevBEA), São Paulo, v. 10, n. 3, p. 177-199, 2015.

MELO, M. R. S.; GUEDES, N. M. R.; SOUZA, C. C. Percepção e valoração ambiental do Parque Estadual Matas do Segredo em Campo Grande, Mato Grosso do Sul. (Perception and valuation environmental of Parque Estadual Matas do Segredo in Campo Grande, Mato Grosso do Sul). Revista Brasileira de Geografia Física, Recife, v. 9, n. 5, p. 1513-1528, 2016.

MELO, M. R. S.; SOUZA, C. C; GUEDES, N. M. R. Contribución del ecoturismo a la conservación del guacamayo rojo (arara-vermelha) en una reserva de Brasil. Estudios y perspectivas en turismo, v. 27, n. 1, p. 158-177, 2018.

PLANURB- Instituto municipal de planejamento urbano. 2017. Perfil socioeconômico de Campo Grande. Campo grande, MS: Prefeitura municipal de Campo Grande. Disponível em <http://www.campogrande.ms.gov.br/ sedesc/downloads/perfil-socioeconomico-de-campo-grande/>. Acesso em: 13 mar. 2018.

SAUER, L.; CAMPÊLO, E.; CAPILLE, M. A. L. Mapeamento dos índices de inclusão e exclusão social em Campo Grande - MS: uma nova reflexão. Campo grande, Ms: Ed. Oeste, 2012. 68p.

$\mathrm{SCHUCH}, \mathrm{M}$. I. S. Arborização Urbana: uma contribuição à qualidade de vida com uso de geotecnologias. 2006. 102f. Dissertação (Mestrado em Geométrica) - Centro de Ciências Rurais, Universidade Federal de Santa Maria, Santa Maria.

SICK, H. Ornitologia Brasileira. Edição revista e ampliada. Rio de Janeiro: Ed. Nova Fronteira, 1997. 882p.

TOLEDO, M. C. B. Análise das áreas verdes urbanas em diferentes escalas visando a conservação da avifauna. 2007. 149f. Tese (Doutorado em Zoologia) - Instituto de Biociências de Botucatu, Universidade Estadual Paulista. Botucatu.

TUAN, Yi-Fu. Topofilia - Um estudo da percepção, atitudes e valores do meio ambiente. Londrina: Eduel. 2012. 342p.

VILLAR, L. M.; ALMEIDA, A. J.; LIMA, M. C. A.; ALMEIDA, J. L. V.; SOUZA, L. F. B.; PAULA, V. S. A percepção ambiental entre os habitantes da região noroeste do estado do Rio de Janeiro. Escola Anna Nery Revista de Enfermagem, Rio de Janeiro, v. 12, n. 2, p. 285-290, 2008.

WILSON, E. O. Biofilia. México: Fundo de Cultura Económica, 1989. 283p. 